\title{
Study of Esterification Waste water Treatment by Different Flocculants
}

\author{
Yan bin Yun ${ }^{1 *}$, Zhen bang $\mathrm{Li}^{1}$, Chen Guo , Juan hong Wei ${ }^{1}$, Jing jing $\mathrm{Li}^{1}$, Zhong qiang $\mathrm{Cao}^{2}$ \\ ${ }^{1}$ School of Environmental Science and Engineering, Beijing Forestry University, China \\ ${ }^{2}$ Beijing Huateng High technic Corporation, Beijing, China
}

Submission: May 08, 2016; Published: October 12, 2016

*Corresponding author: Yan bin Yun, School of Environmental Science and Engineering, Beijing Forestry University, China.

\begin{abstract}
In this study, the Esterification wastewater was treated by three kinds of flocculants (poly aluminum chloride (PAC), polymeric ferric sulfate (PFS), poly aluminum ferric chloride (PAFC)) and two kinds of coagulant aid (cationic poly acryl amide (CPAM) and anionic poly acryl amide (APAM)). The influences of flocculent concentration, coagulant aid concentration, wastewater temperature and pH on the treatment performance based on the removal rate of $\mathrm{COD}_{\mathrm{cr}}$ and turbidity were investigated. Compared with PFS and PAFC which COD removal rate were $32 \%$ and $37 \%$, PAC had the highest $\mathrm{COD}_{\text {cr }}$ removal rate $(51.8 \%)$ when wastewater $\mathrm{pH}$ was 10 , temperature was $35{ }^{\circ} \mathrm{C}$ and $\mathrm{PAC}$ concentration was $6 \mathrm{mg} / \mathrm{L}$. When CPAM and APAM were selected as coagulant aids during flocculation process, COD removal rate was enhanced obviously compared with no coagulant aid, especially that CPAM increased the COD removal rate by $10 \%$, take PAC for example, the highest COD removal rate achieved $60 \%$ when $15 \mathrm{mg} / \mathrm{L}$ CPAM was added.
\end{abstract}

Keywords: Esterification waste water; flocculants; PAC; PFS; PAFC; PAM

Abbreviations: PAC: poly aluminum chloride; PFS: polymeric ferric sulfate; PAFC: poly aluminum ferric chloride; COD: Chemical oxygen demand; CPAM: cationic poly acryl amide; APAM: anionic poly acryl amide

\section{Introduction}

Esterification waste water, which comes from the polymer Esterification process in industry Jing \& Li [1], Zhao [2]. Due to the Esterification reaction reversibility and the slow reaction velocity, concentrated sulphuric acid is adopted to enhance the reaction efficiency as catalyst, as a result, Esterification wastewater has corrosiveness, irritation and toxicity which pose great threat to the environment and human beings if no treated Meric et al. [3], Liu et al. [4], Xu [5]. With the improvement of people's requirement on living quality, the emission standard of Esterification wastewater is higher and higher, treating efforts to Esterification wastewater are enhanced markedly. At present, biological treatment and membrane methods are adopted to treat Esterification wastewater universally, however, due to the features of low $\mathrm{pH}(<4)$, exorbitant concentration $\mathrm{COD}_{\mathrm{cr}}(>18000$ $\mathrm{mg} / \mathrm{L}$ ), and containing an amount of complex components, negative influence on the treatment process is brought, excessive load inhibit microbial growth even lead activated sludge bulking, serious membrane fouling happen, the charge of operation and guidance raise and effluent quality would be lower.

Through some studies of Esterification wastewater, it can be knew that the $\operatorname{COD}_{\text {cr }}$ can decrease efficiently by pretreatment measures with the removal of lightly soluble or insoluble substance in water (terephthalic acid, polyester particles and molecules colloids) which have important contribution to $\mathrm{COD}_{\text {cr }}$ in Esterification wastewater Lu et al. [6], Liao et al. [7], Li [8]. Hence, it's essential to take pretreatment to Esterification wastewater, various traditional and advanced technologies have been utilized, such as precipitation, flotation, solvent extraction, adsorption, coagulation, flocculation, biological and electrolytic method Tian et al. [9]. Among these available methods for wastewater pretreatment, flocculation is a simple, efficient, low cost and energy consuming for the operation so that it's widely used for removing suspended and dissolved solids, colloids and organic matter in wastewater treatment aspect. In this process, with the flocculent added, dispersed particles or colloidal are aggregated to form larger-sized flocs, and sedimentation followed to remove flocs Chong [10], Lee et al. [11], Lee et al. [12].

The flocculants areapplied in industrial wastewatertreatment can be classified into two categories: inorganic flocculants such as metal salts; organic flocculants from polymeric materials generally Wang et al. [13]. The most commonly used inorganic 
flocculants are multivalent metals salts, such as alum, poly aluminum chloride (PAC), polymeric ferric sulfate (PFS), ferrous sulphate, calcium chloride and magnesium chloride, they have been used as flocculants widely due to its feature of efficiency and low cost compared to other chemical flocculants. When the inorganic flocculants added, metal salts would hydrolyse rapidly in wastewater, with the hydrolysate absorbed colloidal particles and insoluble substance, plenty of dense flocs with irregular shape which had good settling characteristic formed, resulting in $\mathrm{COD}_{\mathrm{cr}}$ and turbidity were removed Lee et al. [14], Gregory and Barany [15], Oladoj [16]. During these years, many organic flocculants especially polymeric materials have been used as the main flocculants (or coagulant aids) which could enhance the flocculation efficiency. Polymeric flocculants were used widely include poly acryl amide, poly acrylic acid, poly (di allyl di methyl ammonium chloride) (DADMAC), polyamine and others Tang et al. [17], Das et al. [18]. Poly acryl amide (PAM) is the basis of many commercial organic polymeric flocculants due to it can be easily synthesized and grow up to high molecular weights. Anionic poly acryl amide (APAM) can be produced by copolymerization of acryl amide with acrylic acid, cationic poly acryl amide (CPAM) can be prepared by co-polymerization of acryl amide with cationic monomer, such as DDMAC. To deserve to be mentioned, PAM has better efficiency as coagulant aid than flocculent, appropriate dosage of PAM not only increases density and solidity of flocs, it also reduces the consumption of flocculants and increases efficiency and stability in the flocculent process Wang et al [19], Bharti et al. [20].

In this study, the Esterification wastewater was treated by three kinds of flocculants (poly aluminum chloride (PAC), polymeric ferric sulfate (PFS), poly aluminum ferric chloride (PAFC)), the influences of flocculent concentration, temperature and $\mathrm{pH}$ on the treatment based on removal rate of CODcr and turbidity were investigated by orthogonal experiment method. Then two kinds of coagulant aid (cationic poly acryl amide (CPAM) and anionic poly acryl amide (APAM)) were tested to obtain the effect of coagulant aid concentration on the treatment performance by single factor experiment method. Finally, the optimal flocculation conditions were expected to obtain through the comparison and analysis of experimental results.

\section{Materials and Method}

\section{Materials}

PFS ( $\geq 99 \%)$, PAC $(\geq 99 \%)$, and PAFC ( $\geq 99 \%$ purity, ion degrees $26 \%$ ) were selected as flocculants due to strong charge neutrality in colloids removal and suspended solids removal by hydrolysis product through various flocculation mechanisms. CPAM ( $\geq 99 \%$, cation ion degrees $20 \%$ ) and APAM ( $\geq 99 \%$, anion degrees $20 \%$ ) were dissolved to obtain a certain concentration aqueous solution as coagulant aids. All of them were bought from Henan Huaming water treatment materials Co. Ltd., China. $\mathrm{NaOH}(\geq 96 \%$, analytical pure, Xilong Chemical Co., Guangzhou),
$\mathrm{HCl}$ ( $\geq 99.5 \%$, analytical pure, Beijing Chemical Works), COD (LHDE-100, Lianhua Technology Co., Guangzhou). Esterification wastewater comes from Huateng Wanfuda Fine Chemical Co., Hebei province, the wastewater qualities are shown in (Table 1).

Table 1: Esterification waste water qualities.

\begin{tabular}{|l|l|l|l|}
\hline Index & pH & COD $_{\text {cr }}$ (mg/L) & Turbidity (NTU) \\
\hline Wastewater quality & $2-3$ & $80000-90000$ & $150-200$ \\
\hline
\end{tabular}

\section{Flocculation experiments}

The influence of different inorganic flocculants and flocculation conditions on treating esterification wastewater were investigated by orthogonal experiment method firstly. Three influence factors were selected, A (flocculants concentration, $\mathrm{mg} / \mathrm{L}$ ), B (wastewater $\mathrm{pH}$ ), C (temperature, ${ }^{\circ} \mathrm{C}$ ), each factors had three levels, $\mathrm{L}_{9}(34)$ orthogonal array was conducted. $\mathrm{COD}_{\mathrm{cr}}$ removal rate and turbidity removal rate as evaluation index were used in polar difference analysis to obtain the best flocculation conditions. The experimental orthogonal array was shown in (Table 2). Esterification wastewater were taken into $100 \mathrm{~mL}$ beakers and their $\mathrm{pH}$ were adjusted to $6,8,10$, then different flocculants were added and stirred rapidly for $2 \mathrm{~min}$ at $60 \mathrm{rpm}$, followed by $10 \mathrm{~min}$ at $30 \mathrm{rpm}$ in different temperature $(15,25$, $35{ }^{\circ} \mathrm{C}$ ), and 4 hours was used to settle at room temperature, the supernant was obtained to test the removal rates of CODcr and turbidity to determine the flocculation performance.

Table 2: Experimental orthogonal array.

\begin{tabular}{|c|c|c|c|c|c|c|c|c|c|}
\hline \multirow{2}{*}{ Level } & \multicolumn{3}{|c|}{ PFS } & \multicolumn{3}{c|}{ PFS } & \multicolumn{3}{c|}{ PAFC } \\
\cline { 2 - 10 } & A & B & C & A & B & C & A & B & C \\
\hline 1 & 120 & 6 & 15 & 60 & 6 & 15 & 60 & 6 & 15 \\
\hline 2 & 180 & 8 & 25 & 120 & 8 & 25 & 120 & 8 & 25 \\
\hline 3 & 240 & 10 & 35 & 180 & 10 & 35 & 180 & 10 & 35 \\
\hline
\end{tabular}

Then the influence of different coagulant aid to inorganic flocculants on treating esterification wastewater were investigated by single factor experiment method. CPAM and APAM were added in wastewater with $5,10,15 \mathrm{mg} / \mathrm{L}$ concentration under the best flocculation conditions of PAC and PFS, respectively, their ability of flocculants in removing $\mathrm{COD}_{\mathrm{cr}}$ and turbidity were investigated.

\section{Evaluation}

The $\mathrm{pH}$ value was measured by $\mathrm{pH}$ meter (PHS-3C, Shanghai Tecfront Electronics Co. Ltd.). Turbidity was estimated by nephelometer (HACH-2100Q, American Hach Co. Ltd.). COD removal rate was analyzed to determine the ability of flocculants in removing organic matter by multi parameter water quality analyzer (Lian Hua 5B-3B, Lianhua Technology Co., Guangzhou). 


\section{Results and Discussions}

\section{Orthogonal experiment analysis}

Table 3(a): Orthogonal polar difference analysis of PFS.

\begin{tabular}{|c|c|c|c|c|c|c|c|c|c|}
\hline \multirow{2}{*}{ Number } & \multirow{2}{*}{\multicolumn{2}{|c|}{ A }} & \multirow{2}{*}{ B } & \multirow{2}{*}{ C } & \multicolumn{5}{|c|}{ PFS } \\
\hline & & & & & \multicolumn{2}{|c|}{$\mathrm{COD}_{\mathrm{cr}}$ removal rate $(\%)$} & \multicolumn{3}{|c|}{ Turbidity removal rate (\%) } \\
\hline 1 & \multicolumn{2}{|c|}{120} & 6 & 15 & \multicolumn{2}{|l|}{24.0} & \multicolumn{3}{|c|}{81.9} \\
\hline 2 & \multicolumn{2}{|c|}{120} & 8 & 25 & \multicolumn{2}{|l|}{30.1} & \multicolumn{3}{|c|}{94.3} \\
\hline 3 & \multicolumn{2}{|c|}{120} & 10 & 35 & \multicolumn{2}{|l|}{28.0} & \multicolumn{3}{|c|}{93.5} \\
\hline 4 & \multicolumn{2}{|c|}{180} & 6 & 25 & \multicolumn{2}{|l|}{11.0} & \multicolumn{3}{|c|}{85.3} \\
\hline 5 & \multicolumn{2}{|c|}{180} & 8 & 35 & \multicolumn{2}{|l|}{30.3} & \multicolumn{3}{|c|}{95.7} \\
\hline 6 & \multicolumn{2}{|c|}{180} & 10 & 15 & \multicolumn{2}{|l|}{30.7} & \multicolumn{3}{|c|}{96.0} \\
\hline 7 & \multicolumn{2}{|c|}{240} & 6 & 35 & \multicolumn{2}{|l|}{30.1} & \multicolumn{3}{|c|}{94.7} \\
\hline 8 & \multicolumn{2}{|c|}{240} & 8 & 15 & \multicolumn{2}{|l|}{30.7} & \multicolumn{3}{|c|}{94.0} \\
\hline 9 & \multicolumn{2}{|c|}{240} & 10 & 25 & \multicolumn{2}{|l|}{7.0} & \multicolumn{3}{|c|}{88.5} \\
\hline \multirow{4}{*}{$\begin{array}{c}\mathrm{COD}_{\text {cr }} \text { removal } \\
\text { rate }(\%)\end{array}$} & $\mathrm{k} 1$ & 27.3 & 22.3 & 28.5 & \multirow{4}{*}{$\begin{array}{c}\text { Turbidity removal } \\
\text { rate (\%) }\end{array}$} & $\mathrm{k} 1$ & 90.0 & 87.3 & 90.6 \\
\hline & $\mathrm{k} 2$ & 24.0 & 30.3 & 12.7 & & $\mathrm{k} 2$ & 90.8 & 94.6 & 89.2 \\
\hline & k3 & 23.2 & 21.9 & 30.1 & & k3 & 92.5 & 92.6 & 94.8 \\
\hline & R1 & 4.1 & 8.4 & 17.4 & & R1 & 2.5 & 7.3 & 5.6 \\
\hline
\end{tabular}

Table 3(b): Orthogonal polar difference analysis of PAC and PAFC.

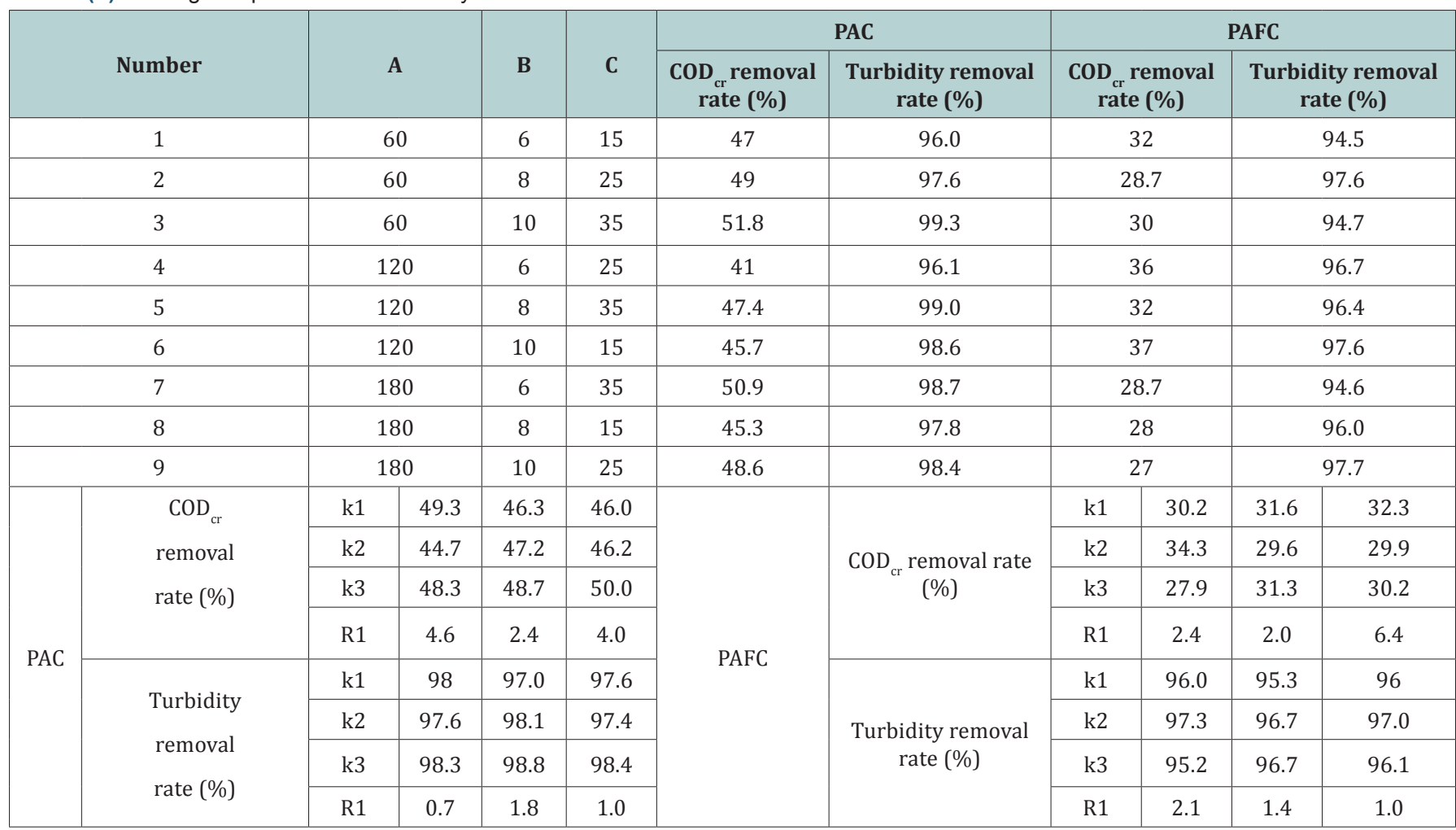

Table 3(a) \& Table 3(b) shows orthogonal polar difference analysis result. It can be seen that when flocculent was PFS and $\mathrm{PAC}$, waste water temperature was the main factor affecting CODcr removal rate while wastewater $\mathrm{pH}$ had the largest influence on turbidity removal rate. When flocculent was PAFC, the influence of wastewater temperature was the biggest on $\mathrm{COD}_{\text {cr }}$ removal rate and turbidity removal rate. After comparing the degree of influence factors, the best flocculation conditions 
were obtained that the flocculants concentration of PFS was 12 $\mathrm{mg} / \mathrm{L}$ at $\mathrm{pH} 8,35^{\circ} \mathrm{C}$, the flocculent concentration of PAC was 18 $\mathrm{mg} / \mathrm{L}$ at $\mathrm{pH} 10,15^{\circ} \mathrm{C}$ and the concentration of PAFC was $6 \mathrm{mg} / \mathrm{L}$ at $\mathrm{pH} 6,25^{\circ} \mathrm{C}$.

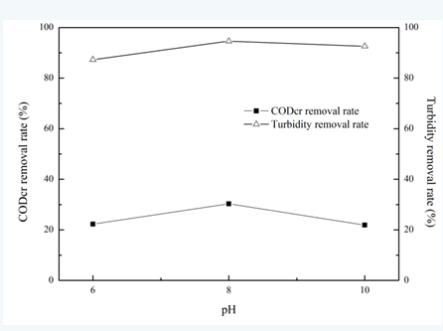

Figure 1: Influence of $\mathrm{pH}$ on CODcr removal rate and turbidity removal rate.

Flocculation performance of PFS: $\mathrm{pH}$ is an important factor on treatment efficiency during flocculation process, $\mathrm{COD}_{\mathrm{cr}}$ removal rate had a trend of increased at first with $\mathrm{pH}$ from 6 to 8 and then decreased with $\mathrm{pH}$ from 8 to 10 , the highest $\mathrm{COD}_{\text {cr }}$ removal rate was $33 \%$ at $\mathrm{pH} 8$ (Figure 1). The reason is that PFS had the best hydrolysis when $\mathrm{pH}$ was 8 , electrically neutral aluminum hydroxide polymer could play the role of adsorption bridging, there were also some hydroxy complex electrical neutralization, larger particle size and dense flocs formed then flocculation affect occurred. The adsorption co precipitation function was strong and newly formed flocs surface activity had net capture, the coagulation effect of PFS was improved greatly. Meantime, the turbidity removal rate had same tendency as $\mathrm{COD}_{\text {cr }}$ removal rate. Turbidity refers to the degree of resistance which was caused by suspended solids when light go through water, the more suspended solids were removed, the lower turbidity was. During flocculation process, the suspended solids were removed mostly and that was why it had same trend with $\mathrm{COD}_{\text {cr }}$ Lee et al. [14].

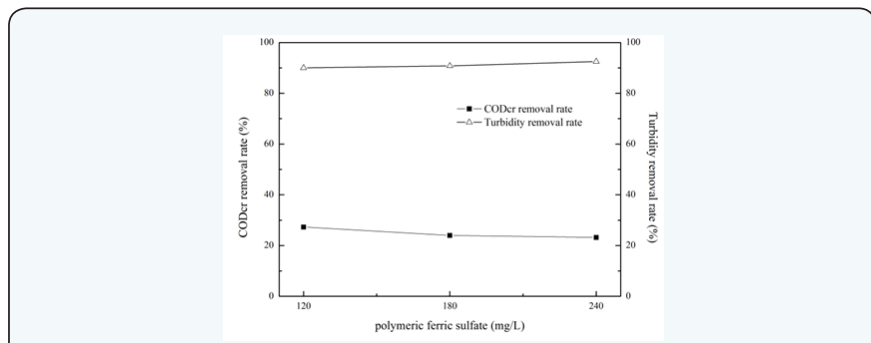

Figure 2: Influence of flocculant concentration on $\mathrm{COD}_{\mathrm{cr}}$ removal rate and turbidity removal rate.

With PFS concentration changed from 120 to $240 \mathrm{mg} / \mathrm{L}$, $\mathrm{COD}_{\text {cr }}$ removal rate decreased slightly and fluctuated in $25 \%$ (Figure 2). This observation was similar to the conclusion by orthogonal polar difference analysis method that PFS concentration had a little influence on $\mathrm{COD}_{\text {cr }}$ removal rate. However, PFS concentration had a certain range, negative effect on treatment would occurred if added too much (>250 mg/L). At the first, flocculants hydrolyzed to high positive ions with flocculent concentration increased, repulsion between the particles fall down via the compression of electric double layer, then combined to flocs closely by adsorption bridging. With the flocculent concentration increased continuously, colloid surface potential gradually decreased to zero, adsorbed in anti-charged particles and repulsion increased.

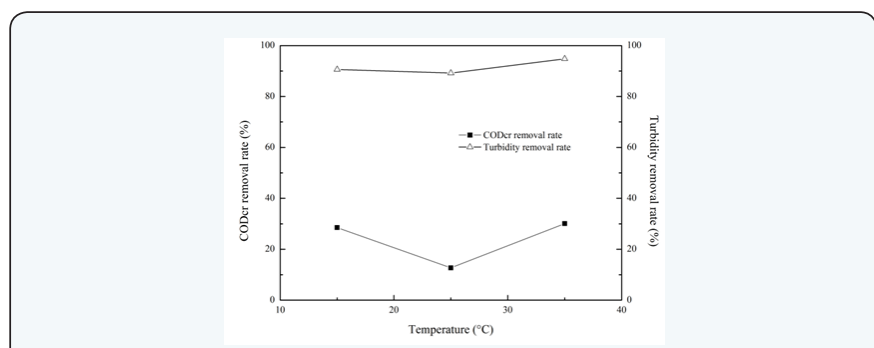

Figure 3: Influence of temperature on $\mathrm{COD}_{\mathrm{cr}}$ removal rate and turbidity removal rate.

The analysis of orthogonal polar difference analysis method shown that temperature was main factor to $\mathrm{COD}_{\mathrm{cr}}$ removal rate, it can be seen that the varied amplitude of $\mathrm{COD}_{\mathrm{cr}}$ removal rate in (Figure 3) was far greater than which in Fig. 2. The $\mathrm{COD}_{\text {cr }}$ and turbidity removal rate were the lowest when temperature was $25 \mathrm{oC}$, and $\mathrm{COD}_{\mathrm{cr}}$ removal rate arrived $30 \%$ when temperature was $35 \mathrm{oC}$. The reason might be that when temperature was lower, Fe3+ had weaker hydrolysis phenomenon, led to less positively charged multi-core hydroxyl ions appeared, electricity neutralization was poor, destabilization of particulate were difficult to occurred and flocculation performance of PFS was not great. When temperature rose up to $35{ }^{\circ} \mathrm{C}$, PFS had higher hydrolysis degree so that flocs were closer and easier to settle Oladoj [16].

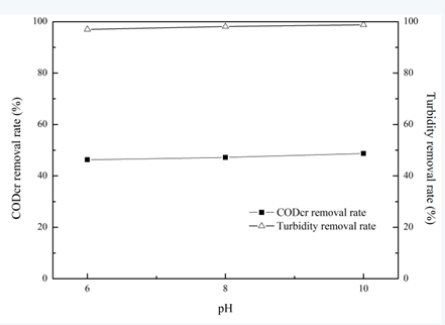

Figure 4: Influence of $\mathrm{pH}$ on $\mathrm{COD}_{\mathrm{cr}}$ removal rate and turbidity removal rate.

Flocculation performance of PAC: With $\mathrm{pH}$ went up, $\mathrm{COD}_{\mathrm{cr}}$ and turbidity removal rate raised gradually (Figure 4), when $\mathrm{pH}$ was 10, COD cr of Esterification wastewater decreased from 95 to $48.5 \mathrm{~g} / \mathrm{L}$ and removal rate was $48.7 \%$. Under neutral or slightly alkaline conditions, $\mathrm{Al}^{3+}$ had strong hydrolysis efficiency, poly nuclear hydroxy complex formed, dispersed colloidal particles flocculated to dense alumen ustum and settled via charge neutralization, and adsorption bridging and aggregation function mechanism. Compared with the trend in (Figure 5), $\mathrm{COD}_{\mathrm{cr}}$ removal rate increased when $\mathrm{pH}$ was in the range of 6-10, it might because that when $\mathrm{pH}>8$, hydrolysis products existed 
mainly in the form of negative ions and precipitation occurred. $\mathrm{Al}(\mathrm{OH}) 3$ precipitation would contribute to the increase of specific surface area, leading the efficiency of adsorption bridging and netting roll sweep effects enhanced further.



Figure 5: Influence of flocculant concentration on CODcr removal rate and turbidity removal rate.

With the PAC concentration from 60 to $120 \mathrm{mg} / \mathrm{L}, \mathrm{COD}_{\text {cr }}$ removal rate decreased from $50 \%$ to $45.3 \%$, and then went up to $47 \%$ when $180 \mathrm{mg} / \mathrm{L}$ PAC added, however, COD removal rate was inversely proportional to $\mathrm{Al}^{3+}$ concentration on the whole. The reason was that too much PAC lead to colloidal particle occurred re-stabilization and was difficult to flocculate.

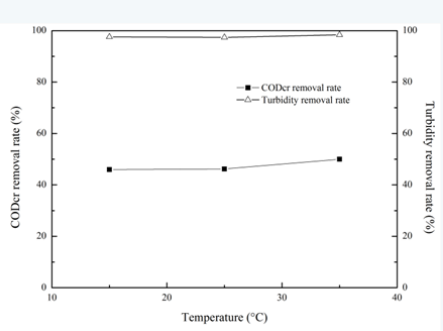

Figure 6: Influence of temperature on $\mathrm{COD}_{\mathrm{cr}}$ removal rate and turbidity removal rate.

When temperature changed from 15 to $25{ }^{\circ} \mathrm{C}$, CODcr removal rate had no obvious change, and then increased to $35{ }^{\circ} \mathrm{C}, \mathrm{COD}_{\mathrm{cr}}$ removal rate increased from 46 to $51 \%$ (Figure 6). A conclusion was obtained that the best flocculation temperature was 35 oC for PAC. When water temperature was low, the brownian movement of colloidal particles became weaker, it was difficult to collide with each other to destabilize and hydration among the colloidal particles were enhanced, which would impede colloid flocculation.

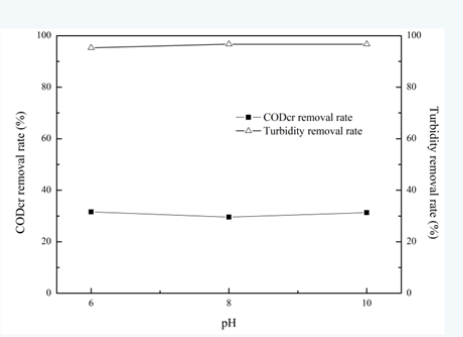

Figure 7: Influence of $\mathrm{pH}$ on $\mathrm{COD}_{\mathrm{cr}}$ removal rate and turbidity removal rate

Flocculation performance of PAFC: Orthogonal polar difference analysis indicated that $\mathrm{pH}$ had a little influence on
$\mathrm{COD}_{\text {cr }}$ removal rate, this can be seen in (Figure 7). When $\mathrm{pH}$ changed from 6 to 10 , removal rate had slight fluctuation $(31.60 \%$, $30 \%, 31.30 \%$, respectively). In aluminum and iron coexistence system, hydrolysis of aluminum and iron were related to each other. On the one hand, aluminum ions promoted the hydrolysis of iron ions, and increased the $\mathrm{pH}$ value of the solution; on the other hand, it restricted further hydrolysis of iron further, meanwhile prevented formation of large polymerization degree iron hydrolyzate and ferric hydroxide sol.

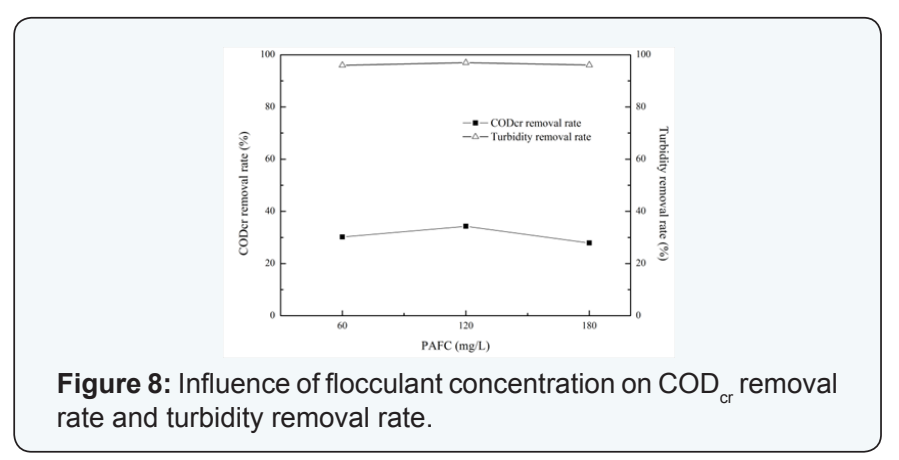

Compared with varied amplitude of $\mathrm{COD}_{\text {cr }}$ removal rate in (Figure 7), it was more obvious than which in (Figure 8). When dozen of PFAC from 60 to $120 \mathrm{mg} / \mathrm{L}$, removal rate went up from $30.2 \%$ to $34.3 \%$, and then decreased to $27.9 \%$ remarkably when $180 \mathrm{mg} / \mathrm{L}$ added. The reason for this phenomenon may be that dispersed colloidal particles had certain electric charge, repellent between each other contributed to colloidal stabilization, once excessive flocculant concentration was added, colloidal particle occurred re-stabilization and difficult to flocculate.

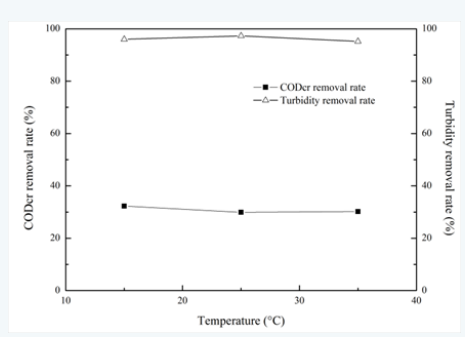

Figure 9: Influence of temperature on $\mathrm{COD}_{\mathrm{cr}}$ removal rate and turbidity removal rate.

As shown in (Figure 9), temperature had a little effect on $\mathrm{COD}_{\text {cr }}$ removal rate but there was a slight change trend on the whole (from $31.6 \%$ to $29.6 \%$ to $31.3 \%$ ), which illustrated that PAFC had better flocculation effect in lower temperature wastewater. The $\mathrm{pH}$ of water was related to water temperature, both of them affect the degree of hydrolysis of flocculent. Coagulant had different forms in water at different temperature and caused different flocculation efficiency.

Effect of flocculation condition on treated wastewater pH: Aluminum and ferric salts have been universally used as flocculants during wastewater treat process, strong hydrolysis would enhance wastewater acidity, this phenomenon was serious especially in Esterification wastewater treatment 
processing, the reason is that Esterification wastewater came from the polymer Esterification process in industry, there are two cases in reaction (carboxylic acid with alcohol; inorganic oxygen acids with alcohol) lead to lots of acidic materials exist in wastewater and the acidity generated via the hydrolysis process cannot be neutralized. The increasing acidity not only decreased treatment efficiency, but also brought negative effect to subsequent biochemical treatment. To obtain great treatment efficiency, alkalies were added in Esterification wastewater to neutralize $\mathrm{H}+$ and enhance alkalinity in flocculation process.

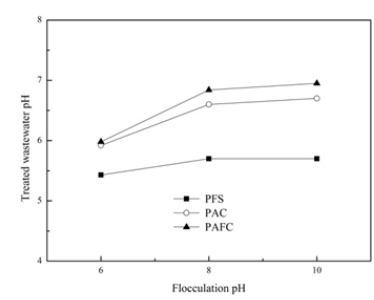

Figure 10: Influence of flocculate $\mathrm{pH}$ on supernatant $\mathrm{pH}$.

As shown in (Figure 10), the $\mathrm{pH}$ of treated wastewater was directly proportional to flocculation $\mathrm{pH}$, with flocculation $\mathrm{pH}$ went up, the $\mathrm{pH}$ of treated wastewater had obvious increase. When flocculation $\mathrm{pH}$ was $10, \mathrm{pH}$ of wastewater which treated by PFS, PAC, PAFC was 5.7, 6.7, 7, respectively. The reason for this phenomenon was that the higher flocculation $\mathrm{pH}$ was, the more $\mathrm{H}+$ which generated by the hydrolysis process were neutralized. With the temperature went up, the $\mathrm{pH}$ of treated wastewater had slightly descent (Figure 11), it might because that as temperature increased, the hydrolysis degree of PFS and PAC enhanced so that wastewater acidity increased. However, a conclusion was obtained that the $\mathrm{pH}$ of wastewater which treated by PAFC always was the highest, it might because that PAFC had complicated hydrolysis component and better cushioning capacity as a compound polymer flocculent.



Figure 11: Influence of flocculate temperature on supernatant $\mathrm{pH}$.

\section{Flocculation performance of coagulant aid}

CPAM was added as coagulant aid (Figure 12), with the concentration increased (from 5 to $15 \mathrm{mg} / \mathrm{L}$ ), CODcr removal rate also went up, the ascend range were small when flocculent were PFS and PAFC (from 32\% to 39\%, 35\% to 40\%, respectively) but increased remarkably (from $36 \%$ to 58\%) when flocculent was PAC. It is frequently found that CPAM for the flocculation of negatively-charged particles and higher efficiency appeared, the reason for this phenomenon might be there is mostly a strong adsorption affinity and neutralization of the particle charge occurs, with more dosage of CPAM added, it played a role that adding inorganic electrolytes, fine suspended particles in the water had collision and formed big flocs to settle because of electricity neutralization mechanism. As shown in (Figure 13), with APAM concentration went up from 5 to $15 \mathrm{mg} / \mathrm{L}$, CODcr removal rate also had a uptrend when flocculent were PFS, PAC, PAFC (from $27 \%$ to $33 \%, 33 \%$ to $39 \%, 38 \%$ to $42 \%$, respectively). The best APAM concentration were $10 \mathrm{mg} / \mathrm{L}$ for PFS, $15 \mathrm{mg} / \mathrm{L}$ for PAC and PAFC, and removal rate were 34\%, $39 \%$ and $42 \%$, respectively. Because that a certain amount of sexual base existed in APAM molecular chain could adsorbed suspended solid particles in Esterification wastewater such as molecules colloids, then enhanced formation of large flocculate via bridging action between particles and flocculation efficiency rose. However, flocculation of CPAM was mainly electrostatic while flocculation by APAM was caused by polymer bridging at high $\mathrm{pH}$ and charge neutralization at low $\mathrm{pH}$ Sanghyun J et al. [21].
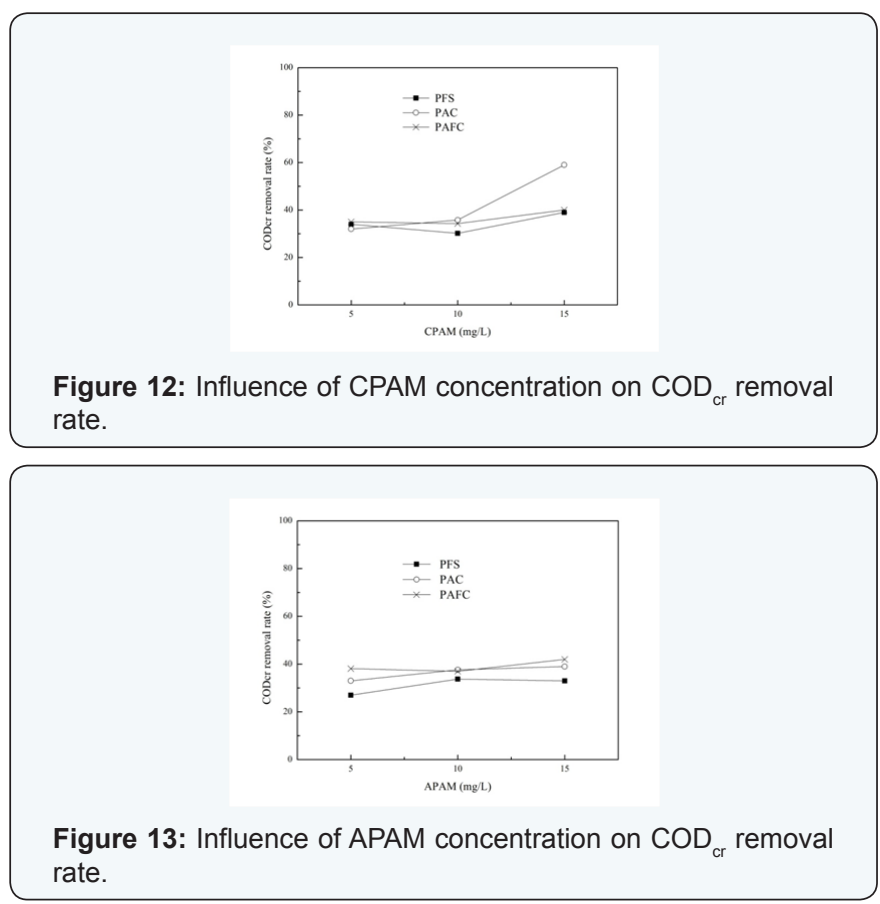

\section{Conclusion}

Three kinds of flocculants (PAC, PFS, PAFC) and two kinds of coagulant aid (CPAM and APAM) were adopted to treat Esterification wastewater in this study, COD $_{\text {cr }}$ removal rate and turbidity removal rate were tested to investigate flocculants efficiency. It was found that (1) orthogonal polar difference analysis result shows that wastewater temperature was the main factor affecting $\mathrm{COD}_{\mathrm{cr}}$ removal rate when flocculent was PFS and PAC and PAFC. (2) in terms of PFS, $\mathrm{COD}_{\text {cr }}$ removal rate increased at first then decreased with $\mathrm{pH}$ raised, decreased with 
PFS concentration grew up and decreased at first and increased with temperature went up. (3) in terms of PAC, $\mathrm{COD}_{\mathrm{cr}}$ removal rate increased with $\mathrm{pH}$ and temperature raised, decreased at first then increased with PAC concentration grew up. (4) in terms of $\mathrm{PAFC}, \mathrm{COD}_{\mathrm{cr}}$ removal rate increased with $\mathrm{pH}$ raised, increased at first then decreased with flocculent concentration grew up and decreased at first and increased with temperature went up.

(4) when PAC concentration was $6 \mathrm{mg} / \mathrm{L}$ at $\mathrm{pH} 10,35^{\circ} \mathrm{C}$, $\mathrm{COD}_{\text {cr }}$ removal rate was the highest(51\%), and it was found that the efficiency of PAC was more stable than others; (5) when CPAM and APAM were added as coagulant aid, COD $_{\text {cr }}$ removal rate increased in $10 \%$ at a whole compared with no coagulant aid added.

\section{Acknowledgements}

This work was financially supported by "the National Nature Science Foundation of China (Grant No. 21376030)".

\section{References}

1. Jing X, Li ZS (2012) Research progress of high concentration organic waste water treatment technology. Chengdu Univ (Natural Science Edition) 31(1): 85-89.

2. Zhao YG (2015) Determination of glycol in esterification process water Technology \& Development of Chemical Industry. 44(5): 55-57.

3. Meric S, Kahdasll I, Tttnay O (1999) Treatability of strong wastewaters from polyester manufacturing industry. Wat Sci Tech, 39(10): 1-7.

4. Liu B, Ji W, Ding CC (2012) Review on treatment technology of Polyester Wastewater Science \& Technology Information. 796-797.

5. Xu J (2014) Introduction to Paint with Resin Production Wastewater Treatment Guangdong Chemical Industry. 41(288): 98-99.

6. Lu DC, Wang XH, Wu CQ (2013) Operation practice of highconcentration esterification waste water treatment project China Water \& Wastewater. 29(22): 113-115.

7. Liao L, Kong W, Cai Q Zhang J, Hu BJ (2014) A engineering of high concentration wastewater esterification treatment via buried ABRbiological contact oxidation process Industrial water \& wastewater. 45(6): 67-69, 73.

8. Li XQ (2014) Polyester wastewater with high concentration treated by fenton - UASB - biological activate carbon. China Adhesives 23(11): 20-24.
9. Tian AJ, Ouyang HL, Zhu ZM, Wang S, Gao M (2011) Polyester wastewater treatment and reuse by anaerobic aerobic-aeration advanced treatment. Pollution Control Technology 24(1): 28-30, 49.

10. Chong MF (2012) Direct flocculation process for wastewater treatment. In: Sharma SK \& Sanghi R (Eds. ), Advances in Water Treatment and Pollution Prevention Springer, Netherlands, pp. 201-230.

11. Lee KE, Morad N, Teng TT, Poh BT (2012) Development, characterization and the application of hybrid materials in coagulation/flocculation of wastewater: a review. Chem Eng J 203: 370-386.

12. Lee CS, John R, Chong MF (2014) A review on application of flocculants in wastewater treatment Process Safety and Environmental Protection. 92: 489-508.

13. Wang S, Liu C, Li Q (2013) Impact of polymer flocculants on coagulation microfiltration of surface water. Water Research 47: 4538-4546.

14. Lee SY A, Fane AG, Waite TD (2005) Impact of natural organic matter on floc size and structure effects in membran filtration. Journal of Environmental Sci and Technol 39(17): 6477-6486.

15. Gregory J, Barany S (2011) Adsorption and flocculation by polymers and polymer mixtures. Advances in Colloid and Interface Science 169: $1-12$.

16. Oladoj N A (2015) Headway on natural polymeric coagulants in water and wastewater treatment operations. Water Process Engineering 6: 174-192.

17. Tang CY, Chong TH, Fane AG (2011) Colloidal interactions and fouling of NF and RO membranes: a review. Adv Colloid Interface Sci 164(1-2): 126-143.

18. Das R, Panda AB, Pal S (2012) Synthesis and characterization of a novel polymeric hydro gel based on hydroxypropyl methyl cellulose grafted with polyacrylamide Cellulose. 19(3): 933-945.

19. Wang CX, Li XT, Wu Y M (2011) Flocculation ability of water dispersion of amphoteric polyacrylamide. Periodical of Ocean University of China 40(1-2): 125-128.

20. Bharti S, Mishra S, Sen G (2013) Ceric ion initiated synthesis of polyacrylamide grafted oatmeal: its application as flocculant for wastewater treatment. Carbohydr Polym 93: 528-536.

21. Sanghyun J, Firoozeh N, Tien V N, Saravanamuthu VT, Anh T (2011) Pretreatment for seawater desalination by fl occulation: Performance of modified poly ferric silicate (PFSi- $\delta$ ) and ferric chloride as $\mathrm{fl}$ occulants Desalination. 283: 106-110.

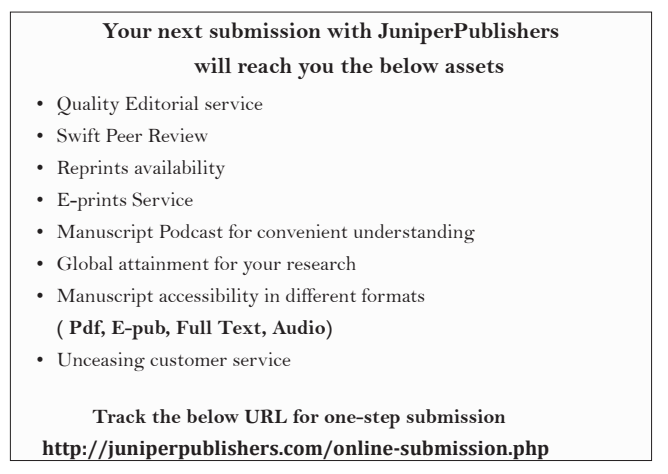

